Jayapangus Press

Jurnal Penelitian Agama Hindu

Terakreditasi Peringkat 2
Volume 5 Nomor 3 (2021)

ISSN : 2579-9843 (Media Online)

http://jayapanguspress.penerbit.org/index.php/JPAH

\title{
IMPLEMENTASI AJARAN YOGA KAPAMANGKUAN DI PASRAMAN MULAT SARIRA DESA ADAT DUDA DESA DUDA TIMUR KECAMATAN SELAT KABUPATEN KARANGASEM
}

\author{
I Wayan Nerta \\ Universitas Hindu Negeri I Gusti Bagus Sugriwa Denpasar \\ yannerta@gmail.com
}

\begin{abstract}
Kapamankuan yoga teachings are part of the implementation of tantric yoga teachings for Pamangku, namely an implementation of yoga teachings that are closely related to sädhāna. My uncle does not only need to be physically fit or physically fit but also mentally and spiritually healthy. Pamangku in his duties nganteb upakara there are steps that are carried out both physically and mentally. Parts of body posture such as the masila den apened sitting position, ngunda bayu or prānāyāma techniques, hand movements (mudras) and mantras or seha are part of the yoga attitude, namely the Kapamangkuan yoga teachings. The Mulat Sarira Pasraman, which is located in the Duda Traditional Village, is a place for deepening the teachings of Hinduism, one of which is the study of Kapamankuan teachings. Departing from this, it is necessary to conduct research, namely: Implementation of Kapamankuan Yoga Teachings, at the Mulat Sarira Pasraman, Duda Traditional Village, East Duda Village, Selat District, Karangasem Regency. Based on this, the problem formulated as follows: The teachings of Kapamangkuan Yoga, what is taught at the Mulat Sarira Pasraman? This study uses a qualitative method with the aim of analyzing the implementation of Kapamankuan yoga teachings at the Mulat Sarira Pasraman. The data from this study were obtained through observation, interviews and document studies. The collected data was verified and then analyzed by Structural Functional theory. The results of the research are the Kapamangkuan Yoga Teachings taught in the activities at the Mulat Sarira Pasraman, namely the Kapamangkuan sesana, the postures of the sitting asana masila pened, the ngunda bayu or prānāyāma breathing arrangements, and the hand gestures or mudras and mantras. As for the findings of this study is the connection between the physical and social body with mental and spiritual awareness. The existence of a social conception of "Kalingsiran" and Pamangku is referred to as a functional position "Jero Mangku," which has dimensions of kapamankuan status. The award given by the community to the title "Jero Mangku" is a specific profession as a liaison that bridges public awareness / Hindus with the abstract realm.
\end{abstract}

Keywords: Yoga Teachings; Kapamankuan Yoga; Mulat Sarira Pasraman

\section{Abstrak}

Ajaran yoga kapamangkuan adalah bagian pelaksanaan dari ajaran yoga tantra bagi pamangku yaitu sebuah pelaksanaan ajaran yoga yang erat kaitannya dengan sādhāna. Pamangku tidak saja dibutuhkan fisik yang sehat atau jasmani yang bugar tetapi juga sehat secara bathin maupun sehat rohani. Pamangku dalam tugasnya nganteb upakara terdapat langkah-langkah yang dilakukan baik secara lahir bathin. Bagian-bagian sikap tubuh seperti 
posisi duduk masila den apened, ngunda bayu atau tehnik prānāyāma, sikap gerakan tangan (mudra) serta mantra atau seha merupakan bagian sikap yoga yaitu ajaran yoga Kapamangkuan. Pasraman Mulat Sarira yang berlokasi di Desa Adat Duda, merupakan tempat pendalaman ajaran agama Hindu, salah satunya pendalaman ajaran Kapamangkuan. Berangkat dari hal itu maka perlu dilakukan penelitian yaitu: Implementasi Ajaran Yoga Kapamangkuan, di Pasraman Mulat Sarira Desa Adat Duda, Desa Duda Timur, Kecamatan Selat, Kabupaten Karangasem. Berdasarkan hal tersebut dirumuskan masalah sebagai berikut: Ajaran yoga Kapamangkuan, apa saja yang diajarkan di Pasraman Mulat Sarira?. Pada penelitian ini menggunakan metode kualitatif dengan tujuan untuk menganalisis implementasi ajaran yoga kapamangkuan di Pasraman Mulat Sarira. Adapaun data dari penelitian ini diperoleh melalui observasi, wawancara dan studi dokumen. Data yang terkumpul diverifikasi kemudian dianalisis dengan teori Struktural Fungsional. Hasil penelitian adalah ajaran yoga kapamangkuan yang diajarkan dalam kegiatan di Pasraman Mulat Sarira, adalah sesana Kapamangkuan, sikap-sikap asana duduk masila pened, pengaturan nafas ngunda bayu atau prānāyāma, serta sika-sikap gerakan tangan atau mudra dan mantra. Adapun yang menjadi temuan dari penelitian ini adalah adanya koneksitas antara secara pisik sosial ketubuhan dengan kesadaran mental spiritual. Adanya konsepsi sosial tentang "Kalingsiran" dan Pamangku disebut sebagai jabatan fungsional "Jero Mangku," yang berdimensi pada status kapamangkuan. Penghargaan yang diberikan masyarakat terhadap sebutan "Jero Mangku" adalah profesi spesifik penghubung yang menjembatani kesadaran masyarakat /umat Hindu dengan alam niskala.

Kata kunci: Ajaran Yoga; Yoga Kapamangkuan; Pasraman Mulat Sarira.

\section{Pendahuluan}

Keberadaan umat Hindu di Indonesia, terlebih pada masyarakat Hindu di Bali hingga kini menganut ajaran Siwa Sidhanta, sebuah paham yang terkait dengan Siva-Buddha Mahayana warisan zaman Hindu Jawa Kuna. Sumadi (2016:1) dalam mengimplementasikan ajaran Agama Hindu, Siwa Sidhanta, umat Hindu menyesuaikan dengan pengetahuan kearifan lokal (local wisdom) dan kekuatan lokal (local genius) Nusantara dan sampai saat ini diwarisi secara turun temurun. Local wisdom dan local genius, suatu bentuk kecerdasan lokal sebagai upaya manusia untuk mencari kebijaksanaan hidup. Local genius menurut Ardana (1986:56, 66,72 ), secara substansial menyangkut inti masalah budaya dan pengembangan kebudayaan nasional. Suatu bangsa dikenal kekhasan citranya berdasarkan 'tanda-tanda pengenal' tertentu. Apabila suatu bangsa, artinya suatu satuan sosial yang memiliki (atau ditandai oleh) satu kebudayaan, juga didukung oleh ciri-ciri rasial maka sering kali ciri-ciri itulah yang pada pandangan pertama seolah menandai jati dirinya. Local genius dalam perspektif agama menurut, Ardana (1986:57, 75) dipahami sesuai dengan pengertian yang diberikan oleh Bosch, yakni merupakan kemampuan untuk mempelajari, menghayati, serta kemudian mengelolanya kembali dan merumuskannya sebagai suatu konsep yang baru.

Tujuan terakhir dari ajaran agama Hindu adalah untuk mencapai kebahagiaan lahir dan bathin. Moksartam jagadhita ya ca ithi dharma yang bearti tujuan beragama dalam ajaran Hindu adalah untuk mencapai Jagathita dan Moksa, Jagathita berarti kesejateraan jasmani, sedangkan Moksa berarti ketentraman bathin, kehidupan abadi dalam panunggalan dengan Ida Sang Hyang Widhi Wasa (Sindhu dkk, 1990: 18).. Upaya untuk mencapai kebahagiaan dan kedamaian itu, salah satu dengan cara selalu berbuat baik (dharma). Seseorang akan dapat berbuat baik apabila selalu berpegang pada wiweka jňāna yaitu kemampuan dalam menimbang dan membedakan antara yang baik dan buruk, antara yang boleh dan tidak boleh dilakukan. Sehingga dengan menggunakan daya wiweka, seseorang akan cendrung diarahkan untuk berbuat yang benar. Di dalam memperkuat wiweka jňāna yang mengarahkan seseorang berbuat baik, manusia harus dalam keadaan sehat, baik secara jasmani dan rohani. 
Menurut Nala (2012:190) Maharsi Ramanuja menyusun suatu rumusan berdasarkan kedua kitab tersebut (Upanisad Karma Kanda dan Adnyana Kanda), bagaimana cara atau jalan terbaik untuk mencapai moksa dan membangun jagaddhita. Jalan atau cara tersebut melalui empat marga utama yang dinamai Catur Marga adalah Bhakti Marga, Karma Marga, Adnyana Marga dan Yoga Marga. Keempat jalan utama ini harus ditempuh bersamaan untuk menuju ke arah yang benar. Bhakti Marga mengutamakan penyerahan diri dan pencurahan rasa, Karma Marga mengutamakan kerja tanpa pamrih untuk kepentingan diri sendiri dimana pengabdian sebagai motivator dari gerakannya, Jnana (Adnyana) Marga dengan jalan ilmu pengetahuan dan Raja (Yoga) Marga mengajarkan pengendalian diri dan konsentrasi (Cudamani, 1987:16). Dari empat jalan atau marga tersebut Raja Yoga merupakan jalan yang dianggap relative sulit. Raja Yoga adalah jalan yang membawa ke penyatuan dengan Tuhan melelui pengekangan diri dan pengendalian pikiran (Sanatana, 2003: 136). Jalan tersebut merupakan sebuah system ajaran yoga yang mengedepankan aspek pengendalian diri dan pikiran. Sumber ajarannya terdapat pada Yoga Sutra Patanjali, Granda Samhita maupun teks lokal Nusantara berupa lontar-lontar di Bali seperti Wrhaspati Tattwa, Jnanasidhanta, Bhuwana Kosa maupun Tattwa Jnana. Dalam Yoga sutra Patanjali terkenal dengan sutranya "yoga's citta vretti nirodhah" (I.2) artinya yoga adalah pengendalian gerak-gerak pikiran (Saraswati, 1979: 279). Ajaran yoga tidak saja dipahami pada kontek phisik saja, tetapi juga pada aspek pikiran. Ajaran yoga pada sumber-sumber tersebut di atas menjadi pedoman hidup kepada siapa saja yang menginginkan tuntunan spiritual, termasuk para Pamangku di Bali. Sebagai seorang Pamangku kebutuhan akan tuntunan pedoman ajaran spiritual sangat melekat pada bidang tugasnya, terutama ajaran yoga seperti Sadānigga yoga pada sumber sastra Nusantara lontar Wrahaspati Tattwa. Supaya orang tidak jatuh ke neraka maka orang harus mengendalikan dirinya dan melaksnakan ajaran etika, sehingga kecendruangan-kecendrungan hati yang buruk dpat dibendung dan kecendrungan hati ysng baik dapat dipupuk. Dalam hunbungan ini Wrahaspatitattwa mengambil astangga yoga ajaran Rsi Patanjali sebagai jalan untuk menguasi diri (Sura, 1985:75).

Pamangku merupakan salah satu pemimpin upacara di samping Sulinggih dalam sebuah pura atau kahyangan di Bali. Dalam bahasa kearifan lokal Pamangku atau pinandita disebut dengan istilah "jan banggul" sebagai istilah seseorang yang telah diyakini dan mendapat tugas mengantarkan upacara. Seseorang dengan sesana Pamangku memiliki tugas dalam menjalankan proses rangkaian upacara piodalan atau pujawali. Dalam mengabdikan diri pada tugasnya, bahwa seorang Pamangku tidak saja dibutuhkan sehat secara fisik atau jasmani tetapi juga sehat secara bathin atau rohani. Hal tersebut memberikan penguatan pada bidang tugas pengabdiannya yang sering disebut ngayah. Pamangku dalam tugasnya ngenterang upakara terdapat langkah-langkah yang dilakukan baik secara lahir maupun bathin. Persiapan secara lahir di samping tetap menjaga kesehatan juga meliputi langkah-langkah perbuatan maupun sikap badan yang dapat mengarah pada sikap bathin. Persiapan secara bathin adalah mulai mengendalikan pikiran, menenangkan pikiran sehingga dapat mengkonsentrasikan pikiran dalam mesehe ataupun mengucapkan mantra. Sebagai pemimpin dalam mengantarkan upakara dalam posisi sesana manut linggih seorang Pamangku tempat duduknya ada di depan para pemedek.

Dalam bahasa symbol Pamangku duduk di depan dapat dimaknai sebagai panutan, ketauladanan baik dari cara berpikir, berbicara maupun berbuat. Sesana seorang Pamangku mengharuskan untuk berupaya mentaati aturan-aturan Kapamangkuan, sehingga akan dituntun untuk persiapan secara lahir maupun bathin. Persiapan secara lahir bathin sangat diperlukan bagi seorang Pamangku, hal ini berkaitan dengan ketenangan pikiran. Pamangku lah yang menyampaikan doa, sebagai penghubung sujud permohonan bhakti dari umat pada saat upacara maupun yadnya di pura. Sebagai penghubung jan banggul maka diperlukan persiapan lahir dan bathin. Bathin yang bersih akan memberikan ketenangan pikiran, dan hal ini berkaitan dengan agem-ageman seorang Pamangku seperti nguncarang atau melapalkan 
seseha, doa atau mantra, maupun tabuh atau suara alunan genta. Asana seperti sikap duduk, sikap tangan dan pranayama merupakan bagian ajaran yoga dari Astangga Yoga Sutra Patanjali, yaitu : Yama, Niyama, Asana, Pranayama, Pratyahara, Dharana, Dhyana dan Samadhi. Dalam istilah local genius di Bali sikap duduk bagi Pamangku disebut dengan masila den apened (duduk bersila). Pranayama disebut dengan istilah ngunda bayu (mengatur nafas), sedangkan mudra / sikap tangan disebut dengan petanganan.

Masila dan ngunda bayu merupakan langkah-langkah persiapan secara bathin untuk mendapatkan ketenangan pikiran bagi seorang pinandita atau Pamangku dalam mesehe. Demikian pula halnya dengan irama dan alunan genta ketika mengantarkan upacara agama memiliki hubungan dengan komponen tubuh itu sendiri. Dengan mengatur jalannya nafas dan merasakan nafas-nafas itu keluar dan masuk, maka perhatian dari pikiran akan terpusat pada jalan nafas itu saja. Hal ini memungkinkan pikiran dapat melupakan tarikan dari benda - benda luar, dan merupakan awal dari latihan membebaskan diri dari pengaruh indra yang lain ( Cudamani , 1987 : 213). Di samping persiapan secara bathin, Pranayama juga memberikan efek pada tubuh itu sendiri. Oleh karena itu Pranayama bagi seorang Pamangku sangat penting dalam kaitannya dengan Kapamangkuan.

Pamangku dalam mengantarkan proses dudonan upacara Yadnya sangat diperlukan kondisi pikiran yang tenang. Dengan kondisi pikirang yang tenang akan berkontribusi dalam pemustan pikiran bagi seorang Pamangku. Dalam beberatan Pamangku pemusatan pikiran disebut dengan Dhyana yaitu bagian dari Dasa Niyama Berata. Dhyana berarti memusatan pikiran atau konsentrasi. Dengan memusatkan pikiran, misalnya hanya tertuju kepada Ida Sang Hyang Widhi, maka seorang Pamangku akan dapat mengendalikan pikirannya agar tidak melanglang buana kesana kemari, dengan demikian ketenangan dan ketentraman pikiran akan mudah tercapai (Suhardana, 2006 ; 42). Pikiran yang tenang tidak kacau berkaitan dengan jalannya nafas. Nafas berubah sesuai dengan keadaan, jika seseorang marah atau mempunyai gangguan-gangguan emosi, laju dan kekuatan pernafasannya meningkat, sedangkan sebaliknya jika senang (tenang) nafasnya pelan dan dalam (Saraswati, 2002:305). Dengan sesana Kapamangkuan bagi sesorang Pamangku maka dengan sendirinya beliau sudah dianggap melakukan (well train) termasuk juga dalam melakukan pranayama.

Menjaga sikap tubuh bagi seorang Pamangku sangat diperlukan, apalagi saat beliau meseha nganteb upakara persembahan di tempat suci. Menata sikap tubuh seperti posisi duduk (masila den apened), petanganan sikap tangan (mudra) dan ngunda bayu tehnik pranayama adalah bagian dari sikap-sikap yoga yang sangat berkaitan bagi seorang Pamangku ketika proses ritual mengantarkan bhakti persembahan umat Hindu. Sikap-sikap tubuh asana yaitu masila,ngunda bayu yaitu tehnik pranayama, sikap tangan (mudra) dan mantra adalah sikap-sikap yoga Kapamangkuan. Dalam aspek ritual Pamangku juga melaksanakan yoga, yaitu yoga Kapamangkuan, sebuah pelaksanaan ajaran yoga tantra yang erat kaitannya dengan aspek-aspek sadhana.

Kabupaten Karangasem merupakan wilayah yang memiliki pura-pura besar di Bali seperti pura Besakih, pura Pasar Agung, pura Lempuyang, pura Andakasa dan pura Silayukti. Setiap pura tersebut terdapat Pamangku sebagai salah satu pemimpin acara pujawali. Pasraman Mulat Sarira adalah suatu wadah kegiatan secara non formal yang berada di Desa Adat Duda, Desa Duda Timur, Kecamatan Selat Kabupaten Karangasem. Salah satu kegiatan Pasraman adalah tentang pendalaman ajaran agama Hindu khusunya bagi para Pamangku. Kegiatan pendalaman ajaran agama Hindu tidak saja dilakukan pada lembaga formal, tetapi dapat juga dilakukan pada lembaga non formal, seperti pada Pasraman. Pendalaman ajaranajaran Kapamangkuan bagi Pamangku seperti ajaran yoga diperlukan dalam tugas dan fungsinya membangun spirit umat Hindu. Dari pernyataan tersebut, ajaran yoga Kapamangkuan seperti sikap sikap duduk, sikap tangan, pranayama (pengaturan nafas) perlu dilakukan bagi seorang Pamangku agar ketika mesehe atau nganteb upakara agar pikiran lebih tenang dalam menjalankan rangkaian upacara yadnya. Berdasarkan hal tersebut maka perlu 
dilakukan penelitian dengan judul: Implementasi Ajaran Yoga Kapamangkuan di Pasraman Mulat Sarira Desa Adat Duda, Desa Duda Timur, Kecamatan Selat, Kabupaten Karangasem.

\section{Metode}

Tulisan artikel ini merupakan sub bagian dari penelitian yang berjudul "Implementasi Ajaran Yoga Kapamangkuan di Pasraman Mulat Sarira Desa Adat Duda, Desa Duda Timur, Kecamatan Selat, Kabupaten Karangasem” (Nerta, 2021). Dalam penelitian ini menggunakan pendekatan kualitatif dengan paradigma interpretatif, yakni penelitian yang menggunakan data secara verbal dan kualifikasi bersifat teoretis. Pengolahan data dilakukan dengan menggunakan pola pikir tertentu menurut logika. Jenis penelitian ini adalah penelitian kualitatif yang berhubungan dengan katagorisasi, karakteristik berwujud pertanyaan atau berupa kata-kata. Penelitian ini lebih banyak membutuhkan jenis data yang berbentuk rangkaian kata-kata bukan angka.

Obyek dari kajian penelitian ini adalah Implementasi Ajaran Yoga Kapamangkuan sebuah penelitian lapangan tentang Implementasi ajaran yoga bagi Pamangku. Pendekatan yang digunakan dalam penelitian ini adalah pendekatan deskriftif kualitatif yaitu suatu metode pendekatan dalam suatu penelitian dengan memberikan definisi secara menyeluruh dari yang bersifat umum ke yang bersifat khusus. Agar suatu penelitian mendapatkan hasil yang diharapkan, perlu adanya pengumpulan data melalui sumber-sumber data yang dapat dipercaya yang dijadikan sumber tinjauan. Sumber data merupakan keterangan-keterangan tentang suatu hal, dapat berupa suatu pengetahuan atau tanggapan (Bungin, 2001:123). Sumber data yang diperoleh dalam penelitian ini adalah data dari tokoh-tokoh agama, masyarakat maupun para Pamangku, dan instruktur yoga, yang dipilih berdasakan pertimbangan memiliki pengetahuan, pengalaman di bidangnya serta memenuhi persyaratan dan dapat dipertanggung jawabkan.

\section{Hasil dan Pembahasan}

Berdasarkan dari latar belakang masalah di atas, maka pembahasan ditekankan pada beberapa pokok-pokok Ajaran Yoga Kapamangkuan yang diajarkan di Pasraman Mulat Sarira di Desa Adat Duda, Desa Duda Timur, Kecamatan Selat Kabupaten Karangasem antara lain :

\section{Sasana Kapamangkuan.}

Dalam Kamus Bahasa Indonesia kata Śāsana diartikan sebagai : $n$ 1. pelajaran ; petunjuk ; nasehat (Tim Penyususn, 1989 : 786). Dalam pengertian yang sama Śāsana juga diartikan sebagai kode etik menurut Subawa (2020:43). .....seorang pamangku juga harus berpegang teguh terhadap śāsana atau kode etik yang harus dilaksanakan ketika menjalankan swadharmanya baik dalam keseharian maupun dalam menghaturkan upakara. Dalam Vrati Śāsana kata Śāsana diartikan sebagai pedoman suci. Tim Penyusun (1995:V) Vrati Śāsana pada dasarnya meupakan inti sari ajaran śāsana yang diperuntukan kepada seorang vratin atau sang sulinggih, pedoman-pedoman suci dharmaning sidanta sudha brata yang semestinya menjadi penuntun abadi dalam kehidupan sehari-hari (termasuk disaat akan" muput Yajnya").

Sasana Kapamangkuan dalam pengertian ini adalah petunjuk, kode etik, pedoman suci seseorang Pamangku yang telah melaksanakan upacara Yajnya pawintenan yang mempunyai tugas pokok memberikan pelayanan kepada umat dalam rangka nganteb upacara yajna. Seorang pamangku sebagai pemimpin upacara wajib menjaga untuk mengendalikan emosi, pengendalian pikiran, perkataan dan perbuatan. Yajnya yang dipersembahkan umat Hindu dengan tulus ikhlas akan kurang sempurna manakala seorang pamangku yang mengantarkan upakara belum mampu dalam mengendalikan emosinya.

Dalam Lontar Kusuma Dewa yang dikutip oleh (Ida Pandita Mpu Jaya Wijayananda, 2003:1) Piteket, kaweruhakena de Sang angelaraken Kapamangkuan : disebutkan tentang seseorang yang melaksanakan gegelaran Kapamangkuan: 
Iti ling Kusuma Dewa. Iki uttamaning pamangku, yening pemgku jagat mangku dalem ngarannya, wenang masuci Purnama muang Tilem, nganggehang brata, yoga Samadhi, satya ring tingkahing kadharman. Mangkana tingkahing mangku jagat.

Terjemahannya:

Inilah ucapan dari Kusuma Dewa. Ini keutamaannya pamangku, bila pamangku jagat, mangku dalem namanya patut menyucikan diri pada purnama maupun tilem, melaksanakan brata, yoga dan Samadhi. Setia terhadap pelaksanaan ajaran kedharman. Demikianlah pelaksanaan seorang mangku jagat.

Seorang pamangku dalam kehidupan sehari-hari wajib menjaga kesucian diri secara lahir dan bathin serta mampu dalam mengendalikan emosinya dengan berpegang pada ajaranajaran dharma. Hal ini disebabkan karena kewajiban yang diemban oleh pamangku cukup berat yaitu mengantarkan bhakti maupun persembahan umat Hindu kehadapan Ida Hyang Widhi Wasa.

Dari kutipan Himpunan Keputusan Seminar Kesatuan Tafsir Terhadap Aspek-aspek Agama Hindu I-XIV tersebut di atas, terdapat sub yang menjadi dasar pokok tentang Śāsana Pamangku yaitu Babratan Pamangku antara lain Yama Niyama Brata. Dalam melaksanakan tugas sebagai Pamangku disiplin tingkah laku yang dijadikan sebagai pedoman Śāsana Pamangku tidak hanya terbatas pada bebaratan tersebut di atas. Terdapat sumber-sumber lain dalam ajaran agama Hindu yang inti ajarannya merupakan bebaratan Pamangku sebagai pedoman suci untuk pengendalian diri. Suhardana (2006:33) mengatakan, ajaran pengendalian diri ini lazim disebut Babratan Pamangku dan ini tercantum dalam Yama Niyama Brata. Yama Brata antara lain Panca Yama Brata, Dasa Yama Brata dan Niyama Brata : Panca Niyama Brata dan Dasa Niyama Brata. Ajaran pengandalian diri sebagai inti dari Śāsana Pamangku adalah berhubungan dengan prilaku kehidupan sehari-hari.

Babratan Pamangku sesungguhnya sudah menjadi bagian pedomana hidup dalam kehidupan sehari-sehari, lebih-lebih pada seorang Pamangku. Walaupun demikian ajaran ini juga diberikan pada Pasraman Mulat Sarira, karena sebagai seorang Pamangku upaya untuk menjaga kesucian diri sangat penting, termasuk pengendalian diri dalam kehidupan sehari-hari. Suhardana (2006 : 34) menyebutkan Panca Yama Brata merupakan "lima cara pengendalian keinginan" tingkat dasar bagi Pamangku. Lima cara pengendalian diri ini adalah :

a. Ahimsa (tidak menyakiti atau membunuh)

b. Brahmacari (berpikir suci, jernih dan jernih)

c. Satya (menjaga kebenaran, Kesetiaan dan kejujuran).

d. Awyawaharika (tidak terikat dengan keduniawian).

e. Asteya atau Asteneya (tidak mencuri).

Ajaran Śāsana Pamangku merupakan sebagai pedoman untuk menjaga kesucian diri pribadinya, dengan melaksanakan brata atau pantangan, di samping juga berupaya untuk berbuat baik bersusila dan menghindari perbuatan yang dursila. Secara umum Śāsana Pamangku banyak terdapat dalam sumber-sumber ajaran kapamangkuan seperti Kusuma Dewa, Sangkul Putih, maupun sumber lain dalam Gagelaran Pamangku maupun Indik Kapamangkuan,

\section{Sikap-sikap Yoga Kapamangkuan}

Seorang Pamangku dalam melaksanakan suatu yadnya atau upacara terlebih dahulu mempersiapkan diri secara lahir dan batin. Persiapan secara bathin dilakukan dengan pengendalian diri dan kesucian pikiran, perkataan dan perbuatan. Sedangkan persiapan secara lahir meliputi sikap-sikap tubuh yang mengarah pada persiapan secara bathin. Langkahlangkah Pamangku dalam melaksanakan suatu yadnya sesungguhnya merupakan pelaksanaan suatu ajaran yoga. Seuai dalam ajaran yoga, terdapat disiplin-disiplin baik secara lahir sampai dengan ajaran yoga dalam konteks bathin menghubungkan diri secara niskala. Sebagai orang yang menjadi pelayan Ida Sang Hyang Widhi Wasa, Pamangku hendaknya setiap hari 
melaksanakan penyucian diri, yang merupakan kegiatan Suci Laksana dengan membacakan mantra tertentu (Suhardana, 2010 :42). Disiplin-disiplin pribadi dalam sehari-sehari merupakan upaya untuk menjaga kesucian diri karena Pamangku disamping sebagai pengayah melayani krama atau umat Hindu juga sebagai pelayan Ida Sang Hyang Widhi Wasa.

a. Sikap asana duduk.

Proses dalam mengantarkan yadnya atau upacara bagi seorang Pamangku diawali dengan langkah penyucian diri. Langkah proses penyucian diri dimulai dari mengambil sikap duduk. Sebelum para Pamangku memulai suatu upacara hendaknya para Pamangku melakukan pembersihan diri dengan tahapan masila den- apened (Ringganatha, 2003:11). Masila denapened adalah istilah dalam bahasa Bali tentang sikap duduk bersila bagi Pamangku di Bali. Cara melakukan sikap duduk bagi seorang Pamangku akan menunjukan sikap bathin. Durasi atau lamanya waktu yang diperlukan bagi seorang Pamangku untuk mengantarkan suatu proses upacara diperkirakan satu setengah sampai dua jam. Lamanya melaksanakan proses upacara tersebut tentu diperlukan sikap duduk yang dapat membantu jalannya pelaksanaan upacara.

Sikap duduk bagi seorang Pamangku dalam proses pelaksanaan upacara tentu berbeda dengan cara duduk bebas seperti biasa tanpa ada aturan yang mengikat. Pada umumnya Pamangku ketika mengantarkan yadnya atau upacara mengambil sikap duduk bersila bagi lakilaki dan bersimpuh bagi yang perempuan. Seorang Pamangku dalam mengantarkan upacara juga memerlukan konsentrasi pemusatan pikairan (Darana) serta arus pikiran yang mengalir bersama doa/ seha (Dhyana). Kedua hal ini merupakan bagian dari Astangga Yoga pada tahap Antarangga. Dharana dan Dhyana adalah merupakan langkah-langkah meditasi dalam ajaran yoga. Seorang Pamangku dalam mengantarkan upacara atau nganteb tidak lepas dari Dharana dan Dhyana, yang juga memerlukan konsentrasi pikiran dan arus pikiran yang mengalir pada obyek pemujan. Sehingga pada saat itu posisi seorang Pamangku juga merupakan sedang bermeditasi. Sikap duduk atau posisi duduk saat itu tidak bisa duduk bebas seperti duduk biasa atau berjongkok, melainkan duduk dengan mengambil sikap meditasi. Saraswati $2002 ; 67)$ tujuan utama dari semua sikap meditasi adalah untuk menjadikan pelaku meditasi duduk dalam satu posisi untuk jangka waktu yang lama. Dalam tingkatan-tingkatan meditasi yang maju, satu posisi harus dipertahankan dalam beberapa jam tanpa menggerakan tubuh dan juga tanpa ada gangguan kenyamanan fisik. Unsur selanjutnya adalah bahwa meditasi yang tinggi memerlukan tulang belakang yang lurus dan beberapa asana juga dapat memenuhi keadaan ini. b. Sikap tangan.

Sikap tangan memberikan gambaran terhadap bahasa tubuh, yang berhubungan dengan pikiran. Sebuah tarian peranan sikap tangan menjadi bagian yang memberikan estetika yang tinggi terhadap tarian itu sendiri. Anggota tubuh bagian tengah mulai dari bahu, lengan atas, lengan bawah dan kesepuluh jari tangan kanan dan kiri menambah eksotisnya sebuah tarian. Lima jari-jari tangan dan kelima jari kiri di samping memberikan estitika dalam sebuah tarian, juga memberikan makna yang mewakili jiwa. Sikap-sikap tangan dalam yoga juga disebut dengan mudra.

Dalam sistem tarian klasik India mudra berarti suatu gerak simbolis dari kedua tangan, yang menimbulkan suasana hati atau emosi tertentu dalam hati. Banyak mudra dalam Yoga juga dilakukan dengan tangan seperti Yoni mudra dan Cin mudra. Ini memberikan tujuan yang sama seperti dalam teknik-teknik tarian untuk memohon suasana spiritual yang memusat ke dalam diri si pelaku. Mudra tertentu juga digunakan untuk mengendalikan proses proses fisiologis di luar kemauan, yang secara normal terjadi diluar kesadaran kita setiap hari (Saraswati, 2002: 348).

Anggota tubuh merupakan sinyal-sinyal yang berhubungan mewakili suasana pikiran. Tangan yang merupakan anggota tubuh bagian tengah, tidak saja memiliki peranan penting dalam aktifitas hidup sehari-hari. Sikap gerakan tangan juga mewakili bahasa tubuh atau gesture seseorang. Cakupan kedua tangan di dada memberikan gambaran yang mewakili pikiran untuk menyampaikan sebuah salam hormat. Gerakan jari-jari tangan kanan dan kiri 
memberikan simbol-simbol makna dalam dunia spiritual. Demikian pula kelima jari-jari tangan seperti ibu jari, telunjuk, jari tengah, jari manis dan kelingking memberikan simbol tersendiri. Mewakili sebuah gesture etika symbol ibu jari dengan jari-jari lainnya ditekuk kerap dipakai untuk menyampaikan tanda yang dimaknai kebaikan.

c. Prānāyāma

Kata Prānāyāma berasal dari bahasa Sansekerta: prana = nafas, kekuatan hidup, kekuatan yang sangat penting atau utama yang meliputi seluruh kosmos; dan yama adalah perluasan, pengembangan, pengendalian. Prānāayama dapat diartikan sebagai suatu rangkaian teknik yang merangsang dan meningkatkan energi yang sangat penting yang pada akhirnya menimbulkan pengendalian yang sempurna pada aliran prana dalam dalam tubuh (Saraswati, 2002 : 301). Ajaran Prāanayama merupakan salah satu dari Astangga Yoga atau delapan bagian Yoga adalah : 1) Yama, 2) Niyama, 3) Asana, 4) Prānāyāma , 5) Pratyahara, 6) Dharana, 7) Dhyana dan 8) Samadi. Dalam lontar Wrahaspati Tattwa, Prāṇāyāma merupakan bagian yang ketiga dari susunan Șậ̄ingga yoga.

Nahan tang Șậàngga yoga ngaranya. Ika ta sadhana ning sang mahyun umangguhakena sang hyang visesa denika, pahawas tang hidepta, haywa ta iwengiweng denta ngrengo sang hyang aji, hana pratyahara yoga ngaranya, hana dhyana yoga ngaranya, hana prāṇāyama yoga ngaranya, hana dharana yoga ngaranya, hana tarka yoga ngaranya, hana samadhi yoga ngaranya (Wrahaspati Tattwa 53).

Terjemahan :

Șaḍàngga yoga menyatakan alat bagi orang yang ingin mencapai sang hyang visesa. Pikiranmu harus tanggap; tidak hanya mendengarkan ajaran suci. Patut kita ketahui pratyahara yoga,dhyana yoga, prānāyāma yoga, dharana yoga, tarka yoga dan samadhi yoga. Ini disebut Șaḍāngga yoga (Putra dan Sadia, 1998 :60).

Saraswati (1979:155 ) Prāñāyāma sebagai arti tehnik khusus sebagai salah satu dari kedelapan sendi Yoga, diciptakan oleh Rsi Patanjali dan dipakai dalam Yoga Sutra. Prāṇāyāma merupakan cara mengendalikan atau pengaturan pernafasan atau pengembangan kekuatan hidup. Secara tradisional prana dalam tubuh di bagian dasar yang dikenal secara bersama-sama dengan Panca prana (lima prana) yaitu prana, apana, samana, udana dan vyana (Saraswati, 2002 : 301).

Dalam bahasa Bali Prānāyāma disebut juga dengan ngunda bayu atau mengatur napas. Dalam berkesenian orang Bali aspek bayu juga merupakan bagian yang membangun taksu yaitu bayu, sabda dan idep. Dengan menguasai semua elemen yang tercakup dalam aspek (bayu) seseorang telah mempelajari keterampilan teknis dari kesenian ini (Dibia, 2014; 86). Bayu bagi seorang penari sangat memegang peranan penting bagi seorang pregina atau penari ketika menari. Seorang pregina jika kurang mensiasati dalam mengatur nafas atau ngunda bayu saat menari di sebuah stage, panggung ( kalangan dalam bahasa Bali ) maka akan kekurangan nafas dan semua itu berpengaruh pada tarian menjadi kurang indah. Pelatih tari Bali menyebutnya agem, tandang tangkep kuang tekek atau gerakan estetika tubuh pada tarinya kurang mantap. Hal tersebut juga disebabkan salah satunya karena kurangnya dalam mengatur nafas.

Prānāyāma dalam yoga adalah latihan untuk mengendalikan pernafasan agar kapasitas paru menjadi lebih besar. Sehingga mampu memasukan udara ke dalam paru lebih besar atau lebih banyak dari pada orang yang tidak melakukan Prạnāyāma atau latihan pengaturan pernafasan. Di samping itu otot - otot punggung dan perut menjadi lebih kuat. Bernapas merupakan salah astu ciri dari mahluk itu hidup. Demikian pula halnya dengan manusia dalam kehidupannya setiap saat selalu dia bernafas. Jika berhenti atau tidak bernapas selamanya maka manusia atau mahlkuk hidup itu sebagai pertanda tidak hidup. Svami Visnudevananda dalam Acarya (2001) mengatakan:

Setiap mahluk hidup bergantung pada pernapasan, dan berhenti bernapas berarti berhenti hidup. Sejak tangisan pertama seorang bayi sampai pada tarikan napas terakhir 
kematian, tidak lain merupakan serangkaian pernapasan. Secara konstan kita memakai "kekuatan hidup" kita atau energy prana kita dalam berpikir, berbuat berkeinginan atau menggerakan otot-otot. Sebagai konsekwensinya perlu adanya penambahan yang konstan yang hanya mungkin melalui pernapasan itu sendiri.

Bernapas memang sudah dilakukan orang sejak dia lahir ke dunia dan bernapas juga tidak ada yang mengajarkannya. Bernapas bagi manusia demikian pula halnya mahluk hidup lainnya merupakan aktifitas yang bersifat otonom, artinya dia berjalan dengan sendirinya tanpa dipengaruhi oleh kesadaran kita. Pada waktu sedang istirahat, tidur, dan bahkan ketika orang pingsan akan terus bernapas. Walaupun bernapas itu bersifat otonum dia berjalan dengan sendirinya, tapi bernapas juga dapat diatur oleh pikiran atau kehendak manusia itu sendiri. Manusia bisa saja menahan napas untuk berhenti bernapas, berhenti menghirup udara. Tetapi aktifitas ini tentu tidak bisa dilakukan dengan durasi waktu yang lama. Manusia hanya bisa berhenti bernapas atau menahan napas hanya beberapa detik atau menit dan tidak mungkin bisa menahan napas selama berjam-jam. Ketika manusia mencoba menahan napas yang lebih lama, terdapat ada sesuatu kekuatan yang melawan kehendak kita untuk menahan napas, sehingga kita kalah dan bernapaslah kita dengan kuatnya (Nala, 1992:132). Seorang atlit pelari 100 meter ketika menjalankan tugasnya lari sekencang-kencangnya, sambil berlari dia akan menahan napas. Tetapi setelah pelari itu sampai mencapai finish dia akan bernapas sekuat-kuatnyanya. Prāṇāyāma bagi Pamangku dalam melaksanakan rangkaian Upacara Yadnya dilakukan disertai dengan konsentrasi.

Prānāyāma :

Om Ang Brahma ya namah (ring Hati)

Om Ung Wisnu ya namah (ring Ampru)

Om Mang Iswara ya namah (ring papusuhan) (Ringganatha, 2003 12).

Prānāyāma yang disertai dengan pikiran berkonsentrasi pada simbol-simbol Ista Dewata dengan sadar mengatur pernafasan, akan dapat menyimpan sejumlah besar prana yang bermanfaat bagi tubuh dan pikiran. Prāñāyāma sebagai satu sistem terdiri dari beberapa aturan mulai dari puraka, menghela napas dengan perlahan-lahan, kemudian menahannya (kumbaka) dan akhirnya melepaskannya dengan perlahan-lahan (recaka) dengan perhitungan $1: 4: 2$ (Pudja, 1991 : 121). Senada dengan itu Nala (2002: 64) mengatakan : Irama pernapasan memegang perana penting, yang ideal adalah : lama menghirup napas (puraka), menahan napas (kumbaka) dan mengeluarkan napas (rechaka) dalam perbandingan $1: 4: 2$. Artinya dari perbandingan itu jika mampu menghirup napas 5 detik, maka tahanlah napas itu di paru selama 4 X 5 detik $=20$ detik, dan menghembuskan 2 X 5 detik $=10$ detik. Rasio Prānāyāma adalah pūraka, kumbhaka dan recaka adalah $1: 4: 2$, pūraka adalah penarikan nafas, kumbhaka adalah penahanan nafas dan recaka adalah penghembusan nafas (Siwananda, 2020 : 51). Mereka yang mempraktekan pernafasan yang dalam dan sistematis dapat merasakan efek yang nyata dari menghiruf prana.

Prānāyāma bukan hanya sekedar menghirup, menahan dan menghembuskan udara dalam tubuh. Kekuatan energi alam yang masuk dalam tubuh dengan doa mantra kekuatan magis maka energi yang terhimpun dalam tubuh akan memiliki kekuatan positif. Seorang yogi yang sempurna dapat menguasi semua rintangan dan menundukkan semua penghalang dengan cara menguasai bioenergi (prana) dengan sebaik-baiknya (Pudja, 1991 : 121). Demikian juga seorang Pamangku melaksanakan Prānāyāma sebagai upaya untuk menghirup energi positif, energi kesucian sehingga dapat melaksanakan prosesi upacara dengan lancar dan sukses. Hal ini bukan saja meningkatkan kuwalitas Yajnya itu sendiri tapi juga dapat meningkatkan kesucian diri dari Pamangku yang nganteb upacara itu sendiri.

\section{Mantra}

Penggunaan mantra dalam ajaran agama Hindu dikaitkan dengan upacara agama adalah erat kaitannya dengan pemujaan Ida Sang Hyang Widhi beserta dengan segala manifestasinya. 
Pudja (1991: 38)... mantra adalah kata-kata yang penuh arti dan rahasia sifatnya. Mantra merupakan rangkaian kata-kata atau beberapa huruf yang dipilih dari bahasa tertentu seperti bahasa sansekerta atau bahasa Jawa kuno. Rumusan kata-kata gaib pada mantra diyakini mengandung kekuatan magis. Suhardana (2006 : 136) kata mantram atau mantra berasal dari bahasa Sansekerta yang terdiri atas dua suku kata yaitu "manas" yang berarti hati nurani dan "trayati" yang berarti menyampaikan. "Manas trayati" disingkat menjadi mantra, dengan demikian berarti menyampaikan hati nurani kehadapan Ida Sang Hyang Widhi beserta manisfestasiNya. Penyampaian hati nurani disampaikan dengan tulus dan ikhlas serta bhakti kepada Ida Sang Hyang Widhi Wasa beserta manifestasiNya, merupakan dasar dari pengucapan mantra. Sementara Chawdhri (2003:97) mendefinisikan mantra sebagai berikut:

Mantra adalah sebuah pola gabungan kata-kata bahasa Veda, yang diidentikkan dengan dewa atau dewi tertentu. Mantra-mantra yang ada sekarang adalah warisan yang kita dapatkan dari para Mahārsi, orang suci, sādhu dan yogi yang telah mempraktekan berbagai mantra itu selama ribuan tahun, kini menuntun kita untuk mengikuti jejak ajaran beliau. Mantra adalah sejumlah huruf, kata yang dijadikan satu. Mantra digunakan dalam sādhana Tantra atau berbagai ritual, diucapkan atau diulang-ulang dalam berbagai kombinasi dan konteks, yang kemudian membuat pola pibrasi tertentu. Seseorang harus belajar untuk mengucapkannya dengan benar dan juga harus memahami artinya (Chawdhri, 2003:97).

Dari kutipan tersebut di atas bahwa mantra dapat disebutkan sebagai pola gabungan kata-kata atau sejumlah huruf yang dirangkai menjadi satu. Mantra sebagai sādhanā tantra atau berbagai ritual diucapkan dengan berulang-ulang, dalam berbagai kombinasi dan konteks, yang kemudian membuat pola pibrasi atau getaran spiritual. Getaran spiritual diyakini ketika mengucapkan mantra dengan benar serta dapat memahami arti dari mantra tersebut.

Penggunaan mantra bagi Pamangku merupakan bagian yang penting dalam prosesi nganteb upakara. Pudja (1991: 38) unsur penting dalam upacara adalah mantra dan stotra, semua upacara diantar dengan mantra-mantra atau stotra. Mantra digunakan untuk menurunkan dewa atau Ida Bhatara ke dalam bentuknya yang sekala niskala.

Pamangku pada saat nganteb upacara sedang melaksanakan yoga yaitu. Menghubungkan diri dengan Tuhan. Menurunkan Ida Sang Hyang Widhi ke dalam bentuk skala-niskala menggunakan sarana-sarana persembahan yang dapat disentuh oleh panca indera. Pujian-pujian (stuti atau stawa) persembahan berupa bunga (puspanjali, sarana upakara), bau harum (dupa, pasepan) gerak tangan yang mempunyai arti magis (mudra), suka kata atau rangkaian kata yang mengandung kekuatan magis dan sakral (mantra). Langkah-langkah Pamangku dalam proses kegiatan upacara tidak lepas dari doa mantra mulai masuk halaman pura, menyapu sampai pada nganteb upakara. Bahkan ketika menjelang tidur pun sesuai dengan Gagelaran Pamangku diawali dengan mantra :

Pacang maturu, mantra: Om Sang Hyang rambut katêmah, umanda ling awak sarira ning ulun, guruning turyan turu awap, najagra ya namah swaha ( Tim Penyusun, 2002:58).

Terjemahan :

Menjelang tidur, mantra: Ya Tuhan, dengan rambut ini (nama yang punya rambut) saya nyatakan tiada berbeda dengan diri saya sendiri. Semogalah tidur dengan lelap. Tiada terbangun. Semoga diberkati.

Di samping menggunakan mantra, Pamangku pada saat nganteb upacara juga menggunakan dengan seha yaitu doa cetusan hati nurani secara tulus ikhlas kehadapan Ida Sang Hyang Widhi Wasa beserta istadewatanya dengan mengkombinasi beberapa bahasa seperti bahasa Sansekerta, Jawa kuno, bahasa Bali kuno atau bahasa Bali kepara. Salah satu Pangastawa / seha Pamangku berdasarkan Gagelaran Pamangku.

Malih nguncarang seha anuwur Bhatara.

Ong pakulun paduka Bhatara manusanta aminta nugraha, ring para Bhatara malejeg maring menyan majegau, muwah ring asep candana, manusanta angulapin, Bhatara 
kabeh, apupul Bhatara ring pasamuan sakti angadeging wong karadan, angundang mukti komala manik ica paduka Bhatara sami tumurun, ngulun angeredana komala kundi sejati, apupul maring sahananing wong ngulun, ngulun pasang tabe angaturi pada paduka Bhatara, asung nugraha tumurun siddha kundi (Tim Penyusun, 2002:69). Terjemahan :

Lagi melantumkan doa mohon kehadiran Bhatara.

Ya Tuhan yang mulia Bhatara, hamba sebagai manusia mohon anugerah, kepada para Bhatara hadir berdiri pada menyan majegau, dan asap cendana, manusia hamba mohon, semua para Bhatara berkumpul di tempat paruman utama, untuk memohon agar perkenan menikmati permata utama, yang mulia semua Bhatara agar berkenan turun, hamba sebagai manusia (komala kundi sejati) berdoa, hamba di antara orang yang berkumpul, hamba mohon izin untuk berkenan kepada yang mulia Bhatara, memberikan nugraha untuk turun (hadir) .

Seha di atas lebih menekankan penggunaan bahasa dengen pendekatan bahasa ibu khususnya bahasa Bali. Suhardana (2006 : 136) Ida Sang Hyang Widhi itu maha tahu, bahasa apapun yang dipergunakan, asalkan Pamangku mengucapkan dengan hati suci, tulus dan ikhlas maka Ida Sang Hyang Widhi akan mengetahuinya. Termasuk juga penggunaan seha Pamangku dengan bahasa Bali, justru umat Hindu di Bali lebih memhami artinya sehingga menambah suasana lebih khusuk.

\section{Kesimpulan}

Berdasarkan pada analisis penelitian yang telah dipaparkan di atas, maka dapat disimpulkan sesuai dengan rumusan masalah pada penelitian ini, yaitu sebagai berikut : Ajaran Yoga Kapamangkuan yang diajarkan dalam kegiatan di Pasraman Mulat Sarira, Desa Adat Duda, Desa Duda Timur, Kecamatan Selat Kabupaten Karangasem adalah Sesana yaitu berupa petunjuk, kode etik, pedoman suci seseorang Pamangku yang telah melaksanakan upacara Yajnya pawintenan yang mempunyai tugas pokok memberikan pelayanan kepada umat dalam rangka nganteb upacara yajna. Ajaran yoga Kapamangkuan berikut yang diajarkan adalah sikap-sikap asana duduk dalam bahasa Bali disebut masila pened, pengaturan nafas yaitu prānāyāma adalah rangkaian yoga Kapamangkuan untuk menuntun pikiran lebih tenang, terkendali, serta sikap-sikap gerakan tangan atau mudra dan mantra. Fungsi dan tugas-tugas seorang Pemangku adalah nganteb mengantarkan upakara yadnya dari sakala menuju niskala, dari material berupa sesajen wewantenan menuju non material berupa doa-doa permohonan kerahayuan. Fungsi dan tugas-tugas seorang Pemangku ketika nganteb mengantarkan upakara yadnya diawali pada pengendalian diri, dilanjutkan dengan sikap duduk yang nyaman pengaturan nafas dan sikap-sikap gerakan tangan dan mantra yang merupakan bagian-bagian dari ajaran yoga.

\section{Daftar Pustaka}

Acharya, A. A. (2001). Yoga Untuk Kesehatan. Jakarta Barat: Persatuan Ananda Marga Indonesia.

Acharya, A. A. (2002). Meditasi Melampaui Batas Kesadaran Supra. Jakarta Barat.: Persatuan Ananda Marga Indonesia.

Anandamurti, S. S. (1998). Dasar Moralitas Kehidupan Spiritual. Jakarta Barat: Persatuan Ananda Marga Indonesia.

Ardana, I. G. (1986). "Local Genius dalam Kehidupan Beragama”, dalam Kepribadian Budaya Bangsa (Local Genius), Penyunting: Ayatrohaedi. Jakarta: Pustaka Jaya.

Atmaja, N. B. (2015). $($ Ngaben + Memukur $)=($ Tubuh + Api $)+$ Uparengga + Mantra $)=($ Dewa Pitara + Surga). Denpasar: Pustaka Larasan bekerja sama dengan IBIKK BCCC Undiksa Singaraja. 
Bhasma IB dan Nengah Sudarma. (1993). Modul Yoga. Jakarta: Dirjen Bimas Hindu dan Budha.

Bungin, B. (2008). Metodelogi Penelitian Kualitatif. Jakarta: PT Raja Grapindo Persada.

Chawdhri, D. L. (2003). Rahasia Yantra, Mantra dan Tantra. Surabaya: Paramita.

Cudamani. (1987). Pengantar Agama Hindu Untuk Perguruan Tinggi. Jakarta: Yayasan Wisma Jakarta.

Cudamani. (1999). Mengatasi Stres Menurut Pandangan Agama Hindu. Surabaya : Paramita.

Dibya, I. W. (2014). Taksu dalam Seni dan Kebudayaan Bali. Denpasar: Bali Mangsi.

Donder, I. K. (2007). Kosmologi HIndu. Surabaya: Paramita.

Nala, Dr.I Gst Ngurah dan Drs. IGK Adia Wiratmadja. (2012). Murdha Agama HIndu. Denpasar: Upastra.

Nala, N. (1992). Kumpulan Tulisan Olahraga. Denpasar: KONI Bali.

Pasek Subawa, I Made dan Putu Sri Junianti. (2020 (Vol.11 No. 1, Maret 2020)). Sasana

Kapamangkuan : Sebuah Ajaran Tattwa dan Etika dalam Membangun Kesadaran Diri

Sebagai Pelayan Umat. SPHATIKA Jurnal Teologi IHDN Denpasar., 42-57.

Penterjemah, T. (1991). Bhuwana Kosa, Alih aksara dan alih bahasa. Denpasar: Pusat Dokumentasi Kebudayaan Bali.

Penyusun, T. (1989). Kamus Besar Bahasa Indonesia. Jakarta: Balai Pustaka.

Penyusun, T. (1995). Vrati Sasana. Denpasar: Bimbingan dan Penyuluhan Kehidupan Beragama, Tersebar di 9 (sembilan ) Dati II.

Penyusun, T. (2002). Indik Kepemangkuan. Denpasar: Pemerintah Provinsi Bali.

Pudja, G. M. (1984). Sraddha. Jakarta: Mayasari - Jakarta.

Pudja, G. M. (1991). Weda Parikrama. Jakarta: Hanuman Sakti.

Punyatmadja, D. I. (1992). Panca Srada. Jakarta: Yayasan Dharma Sarathi

Putra, IGAG dan I Wayan Sadia. (1998). Wrhaspati Tattwa (Alih bahasa). Surabaya: Paramita.

Saraswati, S. S. (1979). Patanjali Raja Yoga, Surabaya: Paramita

Saraswati, S. S. (1996). Patanjali Raja Yoga, Alih Bahasa Mayor Polak. Surabaya: Paramita.

Saraswati, S. S. (2002). Asana, Pranayama, Mudra Bandha. Surabaya: Paramita.

Saraswati, S. S. (2002). Suryanamaskara. Surabaya: Paramita.

Suardana, D. K. (2006). Pengantar Beberatan Pemangku. Surabaya: Paramita.

Suhardana, D. K. (2006). Dasar-Dasar Kepemangkuan, Suatu Pengantar dan Bahan Kajian Bagi Generasi Mendatang. Surabaya: Paramita.

Suhardana, D. K. (2010). Kusuma Dewa, Lima Versi Persamaan dan Perbedaan. Surabaya: Paramita.

Sumadi, I Ketut dan I Wayan Nerta. (2016). Hasil Penelitian : Implementasi ajaran Tattwa, Susila, dan Acara Lontar Tutur Bhuwana Mahbah dalam Kehidupan Umat Hindu di di Desa Pakraman Ekasari, Kec. Melaya, Kab. Jemberana. Denpasar: IHDN Denpasar.

Sura, I. G. (1985). Pengendalian Diri dan Etika dalam Ajaran Agama Hindu. Jakarta: HJanuman Sakti- Jakarta. 